\title{
AN EPIDEMIC OF INFLUENZA B OCCURRING IN A GROUP OF RHEUMATIC CHILDREN CONCURRENT WITH AN OUTBREAK OF STREPTOCOCCAL PHARYNGITIS: CLINICAL AND EPIDEMIOLOGICAL OBSERVATIONS ${ }^{1}$
}

\author{
By GERTRUDE REYERSBACH, T. F. LENERT, AND ANN G. KUTTNER
}

(From Irvington House, Irvington-on-Hudson, $N . Y$.)

(Received for publication December 3, 1941)

During the past three years, 1937 to 1940, the effect of upper respiratory infections on the reactivation of the rheumatic process has been studied at Irvington House, a sanatorium for rheumatic children. During each winter, in addition to sporadic outbreaks of the " common cold," a series of cases of streptococcal pharyngitis developed (1). In February 1940, a third type of upper respiratory infection, epidemic influenza, was observed for the first time. Fifty cases of influenza developed in rapid succession. Dr. Thomas Francis, Jr. of the New York University College of Medicine succeeded in isolating an influenza virus of a hitherto undescribed type, designated as $\mathrm{B}$, from the throat washings of one of the cases (2).

Since this is the first epidemic proven to be due to influenza virus $B$, the clinical and epidemiological findings were considered to be of interest. Furthermore, streptococcal pharyngitis was prevalent in the community, and the opportunity for studying the effect of these two types of upper respiratory infections on each other was excellent.

In 1935, Coburn and Pauli (3) reported an epidemic of "influenza" in a group of rheumatic children which appeared to facilitate the spread of Group A beta hemolytic streptococcus infections. However, it seems possible that this outbreak of upper respiratory disease was not epidemic influenza, since the leukocyte counts of the patients tended to be elevated rather than depressed (4). A ferret pathogenic virus was not isolated.

Since the outbreak of streptococcal pharyngitis began before the epidemic of Influenza $B$, the streptococcal upper respiratory infections will be described first. The type of community and rou-

\footnotetext{
1 This work was aided by a grant from The Commonwealth Fund.
}

tine procedures are described in the preceding paper.

\section{Outbreak of streptococcal pharyngitis: No- vember 2, 1939 to April 19, 1940}

On November 2, 1939, a girl who had had a tonsillectomy in another hospital was readmitted. She had fever for six days after her return, and throat cultures, which had been negative before operation, showed large numbers of Group A beta hemolytic streptococci, Type 27. During November, 4 other girls developed pharyngitis, and their throat cultures were positive for streptococcus Type 27. The infection spread slowly, with 8 cases in December, and reached its peak with 16 cases in January. Three new cases developed in the first half of February, 6 in March, and 1 in April. During the six months when the streptococcal pharyngitis was prevalent, 23 children became carriers of streptococcus Type 27 without developing clinical symptoms.

Clinical findings in 39 children with streptococcus Type 27 pharyngitis. With a few exceptions, all the children complained of sore throat. Thirtythree of the 39 cases had fever ranging from 104.2 to $100^{\circ}$, which subsided after three days in all but 4 instances. The pharynx, in most of the patients, appeared inflamed and slightly edematous. Exudate was noted only in children who had tonsils. Only 2 patients had coryza: Three children developed cervical adenitis with a secondary rise in temperature seven, eight and fifteen days, respectively, after the initial infection. No other complications were observed.

After a latent period varying from eleven to twenty-two days, 8 of these 39 children developed rheumatic recurrences (1).

Laboratory data, streptococcus Type 27 pharyngitis. A well-marked leukocytosis with an increase in the percentage of polymorphonuclear 
cells was the characteristic finding in most of the cases. The total leukocyte counts ranged from 20,700 to 7,400 , with an average count of 13,100 . Following the pharyngitis, 28 children showed a well-defined rise in the erythrocyte sedimentation rate and 10 children a rise in antistreptolysin $\mathrm{O}$ titer.

In February, when the incidence of streptococcal pharyngitis appeared to be declining a sudden outbreak of an acute, febrile disease clinically distinct from the streptococcal infections appeared.

\section{Outbreak of Influenza B: February 16 to March 18, 1940}

On February 16, 1940, a girl developed fever of $100.6^{\circ}$ for one day. She had no complaints and no signs of upper respiratory infection. Her leukocyte count was found to be 5,700. Throat cultures were negative for Group A beta hemolytic streptococci. Three days later a boy complained of malaise and his temperature was 102.4 to $100^{\circ}$ for five days. His leukocyte count was 8,600 . On the following day, 3 more children ( 2 boys and 1 girl) had fever. None of these children complained of "sore throat" or had symptoms suggesting the common cold. The leukocyte counts were uniformly low, and throat cultures were negative for Group A beta hemolytic streptococci. Further cases developed in rapid succession until a total of 50 cases was reached within a period of thirty-one days. The percentage of susceptible individuals, 46 per cent of 108 children, was high. The percentage of girls affected, namely 53 per cent (35 of the 66 girls), was greater than the percentage of boys, 35 per cent (15 of the 42 boys). All the children who contracted epidemic influenza had been in the institution two and one-half months or longer, and were considered to be in good general condition. Half of the 108 children were receiving large doses of vitamins $A, B$ complex, $C$ and $D$, in addition to the regular, well-balanced diet (5). However, the incidence of epidemic influenza in children receiving the same diet without additional vitamins, and those receiving an excess of vitamins, was the same. None of the 40 adults who lived in the institution contracted the disease.

Clinical findings in 50 children with Influenza $B$. The onset was abrupt, with an elevation of temperature. The most common complaints were headache, drowsiness and slight malaise. Thirteen children had no complaints at any time. Mild coryza was noted in 10 of the 50 children on the second or third day of illness. Four children developed a slight cough. Myalgia was present in only 4 instances. The average duration of fever was four days with a maximum of $104^{\circ} \mathrm{F}$. A secondary rise in temperature after one to three days occurred in 7 children. Gastro-intestinal symptoms were not observed. In the majority of children, the symptoms were mild. Physical examination revealed no abnormal findings. The pharynx did not appear inflamed and the lungs were clear. All the children recovered rapidly and no complications of any kind developed. The postinfluenzal lassitude, so commonly seen in adults, was absent. No rheumatic recurrences followed in the wake of the influenzal outbreak.

The contrast in the clinical findings of these two types of upper respiratory infection, streptococcal pharyngitis and Influenza $\mathrm{B}$, was striking and is presented in Table I.

TABLE I

Comparison of complaints and symptoms in 39 cases of streptococcus Type 27 pharyngitis and 50 cases of Influensa B

\begin{tabular}{|c|c|c|}
\hline & $\begin{array}{c}\text { Streptococcal } \\
\text { pharyngitis }\end{array}$ & Influenza B \\
\hline $\begin{array}{l}\text { Complaints: } \\
\text { "Sore throat" } \ldots \ldots \ldots \ldots \\
\text { "Headache" } \ldots \ldots \ldots \ldots \\
\text { Drowsiness...... } \\
\text { Malaise } \ldots \ldots \ldots \ldots \ldots \ldots \\
\text { Myalgia } \ldots \ldots \ldots \ldots \ldots \ldots \\
\text { None } \ldots \ldots \ldots \ldots \ldots\end{array}$ & $\begin{array}{l}35 \text { patients } \\
3 \text { patients } \\
0 \\
1 \text { patient } \\
0 \\
0\end{array}$ & $\begin{array}{l}0 \\
16 \text { patients } \\
13 \text { patients } \\
10 \text { patients } \\
4 \text { patients } \\
13 \text { patients }\end{array}$ \\
\hline 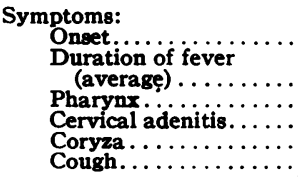 & $\begin{array}{l}\text { gradual } \\
2 \text { days } \\
\text { inflamed, edematous } \\
3 \text { patients } \\
2 \text { patients } \\
0\end{array}$ & $\begin{array}{l}\text { abrupt } \\
4 \text { days } \\
\text { normal } \\
\text { none } \\
10 \text { patients (mild) } \\
4 \text { patients (alight) }\end{array}$ \\
\hline
\end{tabular}

Laboratory data, Influenza $B$. In contrast to the leukocytosis observed in the patients with streptococcal pharyngitis, a relative leukopenia with no increase in the percentage of polymorphonuclear cells was the characteristic finding in cases of the virus infection. The average leukocyte count was 5,600. The range of the leukocyte counts found in these two types of acute respiratory infections is presented in Figure 1.

The percentage of polymorphonuclear cells in the two diseases also showed marked differences 


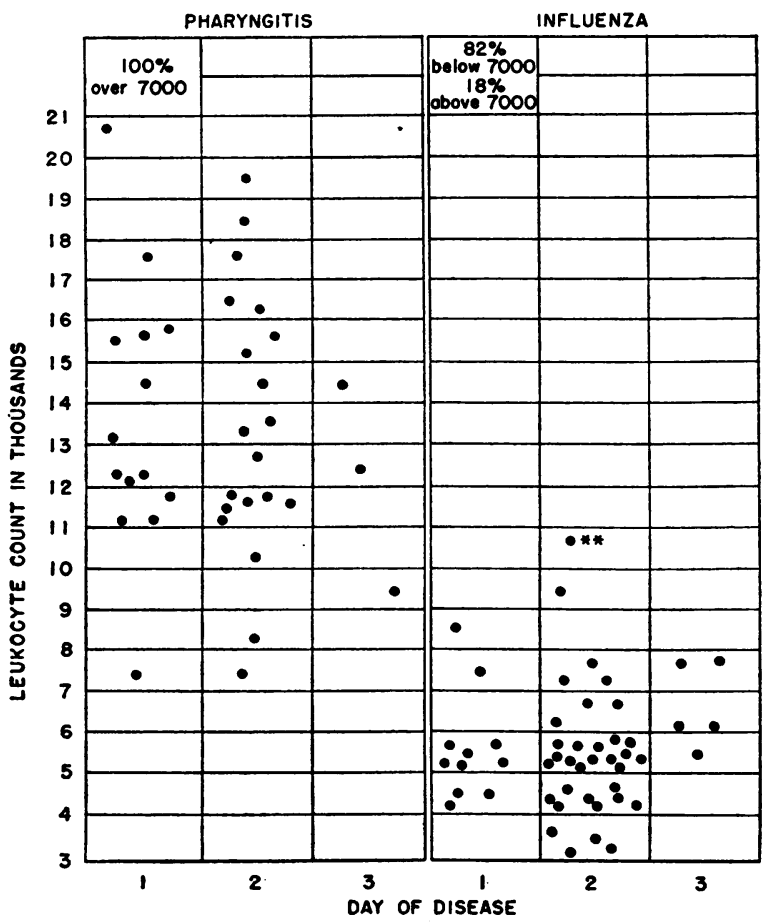

Fig. 1. Leukocyte Count in 50 Cases of Influenza and 37 Cases of Streptococcus Type 27 PharyngiTIS.*

* Leukocyte counts were not obtained on 2 of the patients with streptococcal pharyngitis.

** This child had had infectious mononucleosis. With the onset of Influenza $B$, her leukocyte count dropped from 31,000 to 10,400 in two days.

and is presented in Table II. Only 13 of the 50 children showed a slight transient rise in the erythrocyte sedimentation rate. With the exception of known carriers, throat cultures were uniformly negative for Group A beta hemolytic strep-

TABLE II

Differences in the polymorphonuclear response to streptococcal pharyngitis and Influenza $B$

\begin{tabular}{|c|c|c|c|c|}
\hline \multirow{2}{*}{$\begin{array}{c}\begin{array}{c}\text { Polymorphonuclear } \\
\text { cells }\end{array} \\
\text { Per cent }\end{array}$} & \multicolumn{2}{|c|}{$\begin{array}{c}\text { Streptococcal } \\
\text { pharyngitis }\end{array}$} & \multicolumn{2}{|c|}{ Influenza B } \\
\hline & $\begin{array}{c}\text { Number } \\
\text { of } \\
\text { cases }\end{array}$ & Per cent & $\begin{array}{c}\text { Number } \\
\text { of } \\
\text { cases }\end{array}$ & Per cent \\
\hline $\begin{array}{l}90, \text { or above } \ldots \ldots \\
80 \text { to } 90 \ldots \ldots \ldots \\
70 \text { to } 80 \ldots \ldots \ldots \\
60 \text { to } 70 \ldots \ldots \ldots \\
60, \text { or below } \ldots \ldots\end{array}$ & $\begin{array}{r}1 \\
8 \\
15 \\
10 \\
3\end{array}$ & $\begin{array}{r}2.6 \\
21.6 \\
40.5 \\
27.2 \\
8.1\end{array}$ & $\begin{array}{r}4 \\
19 \\
27\end{array}$ & $\begin{array}{r}8 \\
38 \\
54\end{array}$ \\
\hline Total... & 37 & 100.0 & 50 & 100 \\
\hline
\end{tabular}

tococci. No rise in antistreptolysin O titer occurred.

Epidemiological data. Not only the clinical and laboratory but also the epidemiological picture of the two diseases varied greatly. In contrast to the streptococcal epidemic, the onset and termination of the influenza outbreak were abrupt, a total of 50 cases developing within a period of thirtyone days. The difference in the mode of spread of the streptococcal pharyngitis and the Influenza $\mathrm{B}$ is presented in Figure 2.

\section{The relationship of the influenza epidemic to the outbreak of streptococcal pharyngitis}

Thirty-two cases of streptococcus Type 27 pharyngitis had occurred in the community before the beginning of the influenza epidemic on February $16,1940$.

During the first twelve days of the influenza outbreak, when 25 cases of the virus infection developed, no new cases of streptococcal pharyngitis were observed. During the second half of the influenza epidemic, when 25 more cases of influenza appeared, only 2 children who escaped the virus infection developed streptococcal pharyngitis. From March 19 to April 19, when the influenza outbreak was over, 5 new cases of streptococcus Type 27 pharyngitis developed. Three of these 5 children had escaped Influenza B. Only 2 patients who had had influenza subsequently contracted the streptococcus Type 27 pharyngitis; in one case, the interval between the virus and streptococcal infections was two weeks, and in the other, four weeks. The clinical findings in these 7 children were similar to the 32 cases of streptococcal pharyngitis which occurred before the influenza outbreak. No increase in severity of the symptoms was observed and no complications developed.

Of the 50 children who contracted Influenza B, 21 had had streptococcus Type 27 pharyngitis. Twelve of these 21 patients were still carrying streptococcus Type 27 during the influenza epidemic. Nine children who had become carriers of streptococcus Type 27 developed influenza. No increase in the number of streptococci carried by these children was detected. Two children who developed influenza were carriers of Group A beta hemolytic streptococci of undetermined types. No evidence of spread of these organisms 
was observed. The data in regard to previous and subsequent infection with streptococcus Type 27 and the number of streptococcus carriers in the group of 50 patients with Influenza $B$ are presented in Figure 3.

\section{DISCUSSION}

In the past few years, several outbreaks of acute respiratory disease clinically indistinguishable from epidemic influenza have been reported in which attempts to isolate an etiological agent were unsuccessful and no relationship to known strains of influenza virus could be established (6). In a recent article (7), it was suggested that the term Influenza A should be used to designate infections caused by any of the known strains of influenza virus, and that new types of virus could then be named Influenza $B, C$, et cetera.

The outbreak of epidemic influenza occurring at Irvington House, described in this paper, is of special interest because a new virus serologically distinct from Influenza A was isolated by Francis (2). Furthermore, by immunological studies this author showed that the same or a very closely related etiological agent was also responsible for other epidemics occurring in widely separated parts of the United States of America. In accordance with the terminology recently suggested (7), Francis has designated this virus Influenza B (2).

The symptoms caused by Influenza B closely resembled those associated with Influenza $A$. The disease was mild, with constitutional rather than catarrhal symptoms predominating. The leukocyte counts in the 50 Influenza $B$ patients consistently showed a relative leukopenia.

Cases of pharyngitis due to a single type of Group A beta hemolytic streptococci, Type 27, were prevalent in the community before the outbreak of Influenza B. No evidence was obtained to suggest that Influenza B facilitated the spread of Group A beta hemolytic streptococci.

The epidemiology, as well as the clinical and laboratory findings in these two types of acute respiratory disease, differed greatly. The explosive character of the Influenza B outbreak indicated that all the susceptible individuals in the

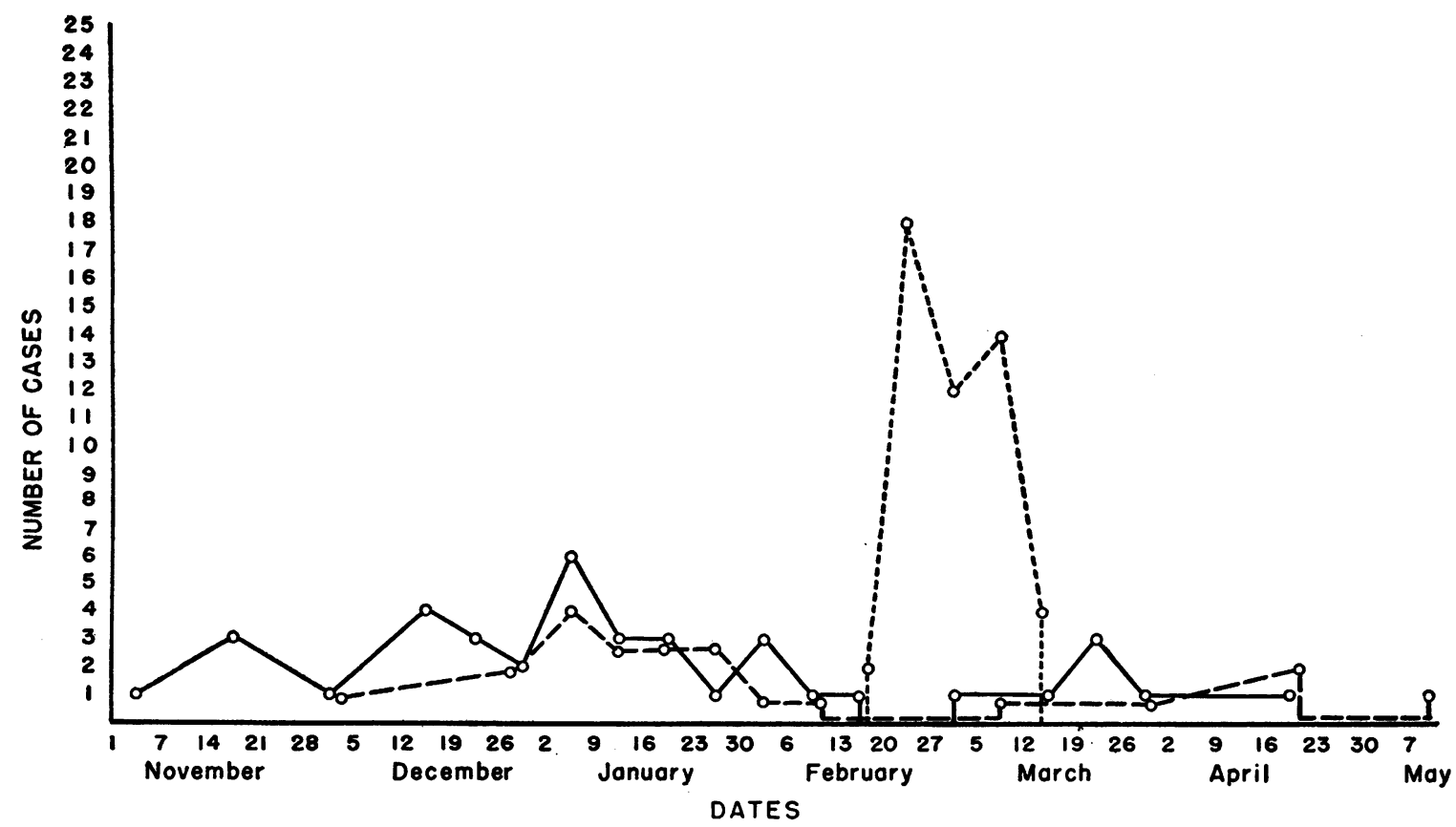

Fig. 2. Weekly Incidence of Streptococcal Pharyngitis and Epidemic Influenza from November 1939 TO JUNE 1940

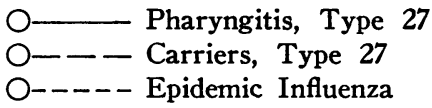




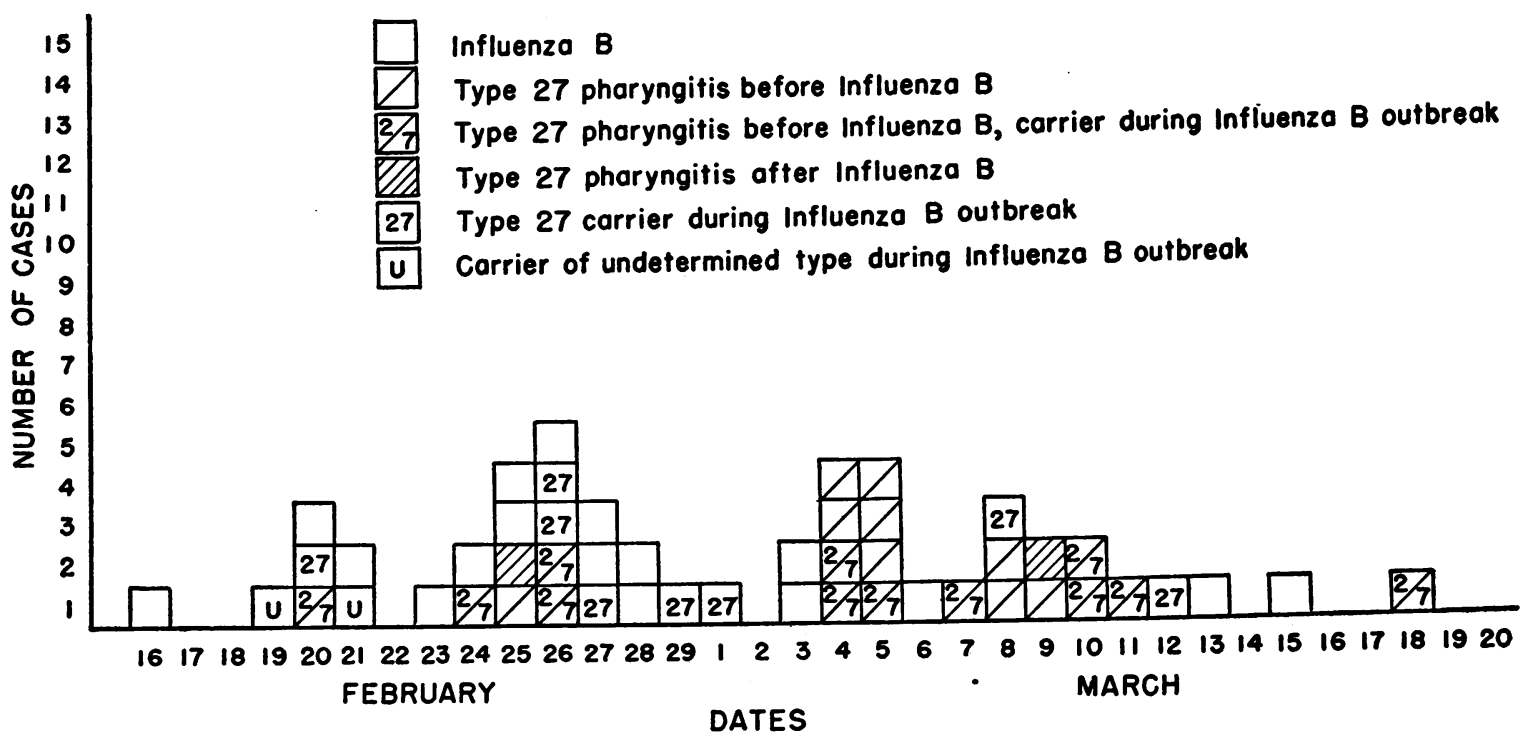

Fig. 3. Data of Previous and Subsequent Infection with Streptococcus Type 27 and the Number of Streptococcus Carriers in the Group of 50 Patients with Influenza B

community contracted the infection in a relatively short time. Susceptibility to the streptococcus Type 27 pharyngitis was much less marked, since new cases developed over a period of six months. Furthermore, the susceptibility of the same child seemed to vary from time to time because, in a few instances, in spite of intimate exposure to an acute case of the streptococcal infection, children failed to develop pharyngitis, only to contract the disease several weeks later.

The most striking difference in the clinical picture was the absence of signs and symptoms referable to the upper respiratory tract in most of the cases of Influenza B. In the streptococcal infections nearly all the patients complained of "sore throat," and definite inflammation of the pharynx was usually apparent. The laboratory finding of the greatest value in establishing the diagnosis of Influenza B was the leukocyte count. By means of the leukocyte count, it was usually possible to differentiate cases of the virus infection from cases of streptococcus Type 27 pharyngitis on the first day of disease. A relative leukopenia was found in all the patients with Influenza B and a definite leukocytosis in the majority of patients with the streptococcal infection. Following a latent period 8 , or 20 per cent, of the 39 patients who had the streptococcus Type 27 pharyngitis developed rheumatic recurrences, whereas no in- stance of a reactivation of the rheumatic process was observed following Influenza B.

\section{CONCLUSIONS}

1. An outbreak of influenza due to a recently described influenza virus, Influenza B (2), in a relatively isolated group of rheumatic children has been described.

2. The clinical symptoms were mild and remained remarkably uniform throughout the epidemic. No complications of any kind developed.

3. The characteristic laboratory finding was a relative leukopenia.

4. No evidence was obtained to suggest that the virulence of a Group A beta hemolytic streptococcus of proven pathogenicity was increased by this strain of influenza virus.

5. Rheumatic recurrences were not precipitated by the influenza outbreak.

\section{BIBLIOGRAPHY}

1. Kuttner, A. G., and Krumwiede, E., Observations on the effect of streptococcal upper respiratory infections on rheumatic children: a three-year study. J. Clin. Invest., 1941, 20, 273.

2. Francis, T., Jr., A new type of virus from epidemic influenza. Science, 1940, 92, 405.

3. Coburn, A. F., and Pauli, R. H., Studies on the immune response of the rheumatic subject and its relationship to activity of the rheumatic process. 
II. Observations on an epidemic of influenza followed by hemolytic streptococcus infections in a rheumatic colony. J. Exper. Med., 1935, 62, 137.

4. Dochez, A. R., Mills, K. C., and Kneeland, Y., Jr., Study of etiology of influenza. Proc. Soc. Exper. Biol. and Med., 1934, 32, 406.

5. Kuttner, A. G., The effect of large doses of vitamins $A, B, C$ and $D$ on the incidence of upper respiratory infections in a group of rheumatic children. J. Clin. Invest., 1940, 19, 809. 6a. Andrewes, C. H., Laidlaw, P. P., and Smith, W., Influenza: observations on the recovery of virus from man and the antibody content of human sera. Brit. J. Exper. Path., 1935, 16, 566.

b. Francis, T., Jr., Epidemiological studies in influenza. Am. J. Pub. Health, 1937, 27, 211.

c. Martin, A. E., and Fairbrother, R. W., An epidemic of apparent influenza. Lancet, 1939, 2, 1313.

7. Horsfall, F. L., Jr., and others, The nomenclature of influenza. Lancet, 1940, 2, 413. 